\title{
Emotional competencies in the process of teaching and learning in nursing, from the perspective of the neurosciences ${ }^{1}$
}

\author{
Wilza Rocha Pereira ${ }^{2}$ \\ Mara Regina Rosa Ribeiro ${ }^{3}$ \\ Valéria Binato Santili Depes ${ }^{4}$ \\ Neuci Cunha Santos ${ }^{3}$
}

\begin{abstract}
Objective: to investigate aspects of the interaction which occurs between feeling and learning from the perspective of the neurosciences. Method: research with a qualitative approach, of the case study type, undertaken in Brazilian public nursing colleges. The research subjects were lecturers and students. The techniques of use of a questionnaire, individual interviews and a focus group were used in data collection. Results: knowledge of cerebral functioning and the functioning of different structures involved in the learning of cognitive, technical, emotional and relational competences can help the lecturer in her task of teaching. Conclusions: we can outline the difficulties of learning and need, as lecturers, to develop teaching strategies based in the new knowledge from the neurosciences so as to maximize the students' learning. This new knowledge brings elements which contribute to the teacher's training, facilitate the process for the person learning, and make teaching more pleasurable.
\end{abstract}

Descriptors: Nursing; Education, Nursing; Learning; Emotions; Neurosciences.

\footnotetext{
${ }^{1}$ Supported by Conselho Nacional de Desenvolvimento Científico e Tecnológico (CNPq), process \# 409575/2006-2.

2 PhD, Associate Professor, Faculdade de Enfermagem, Universidade Federal de Mato Grosso, Cuiabá, MT, Brazil.

${ }^{3}$ PhD, Adjunct Professor, Faculdade de Enfermagem, Universidade Federal de Mato Grosso, Cuiabá, MT, Brazil.

${ }^{4}$ Master's student, Faculdade de Enfermagem, Universidade Federal de Mato Grosso, Cuiabá, MT, Brazil.
} 


\section{Introduction}

Since 1999 the Organization for Economic Cooperation and Development (OECD/Europe), has been joining forces to better understand the process by which humans learn. To this end, it launched a wide project, in two phases of implementation, under the direction of the Centre for Research and Innovation in Teaching (CRIT*). The first phase began in 1999 and ended in 2002, resulting in the text "Understanding the brain: towards a new science of learning'(1), which brought together groups of international researchers in various forums to examine the implications of the recent discoveries regarding sciences of the brain and learning, and to provide more reliable data for supporting political decision-making processes on a global scale concerning the learning process at all levels of teaching.

In the project's second phase (2002 - 2006), works were undertaken based on transdisciplinary international networks in which cognitive neuroscientists confronted questions of direct interest to education. The project's peak was the 2006 publication of the text "Understanding the brain - the birth of a learning science"(2), which became essential reading for all those involved in education - parents, teachers, researchers and formulators of public policies, as well as learners themselves. One of the objectives of investigating the brain is to encourage dialog between educators and neuroscientists, for a better understanding of the intricate processes which learning demands.

From the point of view of the neurosciences, the competences most required at a cerebral level for humans to learn are listed as cognitive, technical, relational, and lastly emotional. This last is of particular interest to this article. It is important to highlight that "each of these fields of competences has its own particular way of learning, its own particular memory system, and even its own specific nervous structures", that is to say, they require specific areas of cerebral functioning(3). Different areas of the brain respond to each type of learning, and there may or may not be interdependence between these different areas for the learning to occur(3).

There are highly accentuated differences in the areas of the brain linked to one or other types of competence. Hence, the cognitive competences are processed by the cerebral structures of the hippocampus and the prefrontal cortices. These are the main areas of the brain involved and required for this type of competence. In the acquisition of competences defined as technical or procedural, on the other hand, there is the direct involvement of the structures of the parietal cortex and the fusiform gyrus. Procedural competence refers to skills and "is supported in procedural memory, that is, in the memory of operational actions and knowledges"(3), and its main function is 'doing'.

Relational competence, actioned in the cortex, "allows us to interact with other people ${ }^{(3)}$ " and has, as its principal function, communication. In order to acquire and develop emotional competences, we commandeer the left and right prefrontal lobes, intermediated by the structure termed the cerebral amygdala, which works in strict conformity with the prefrontal lobes. The amygdala can "shelter memories and repertoires of responses which we interpret without understanding well why we do so, [...] our emotions may have their own mind which may have opinions fairly independently of our rational mind"(4).

It is believed that, in spite of their possessing independent cerebral functioning, these competences are interdependent, and scholars in the neurosciences argue that the "core of learning is not in the cognitive competences, but in the emotional competences ${ }^{(3)}$ ".

The neurosciences are making rapid progress in knowledge about the mechanisms which help us to learn, and have also identified some elements which hinder or impair this process $^{(1)}$. In this research, we address aspects directly linked to emotional competences, which can support or hinder us in the process of learning, and which need to be part of the university teacher's knowledge and technical mastery.

How are we, as teachers, to become more committed to the emotional management of the learning? How are we to obtain better results in the teaching of nursing, the knowledge area of which we speak? These questions lead to the idea that, as lecturers, we need to open ourselves to learn, and incorporate new knowledges which are more in the field of pedagogy and psychophilosophy of learning, which go beyond specific content and the mastery of technical skills which the training in our area demands.

How do we learn, and why? What is it that impedes or impairs us in the process of learning new things and perfecting the knowledge that we already have? What is the place of the teacher in these processes, and what is required of her? How can this professional facilitate or hinder the learning of her students?

* Centre pour la Recherche et I'Innovation dans I'Enseignement 
It is necessary to 'feel' to 'learn'. How should one interpret this simple phrase? We start from the idea that various emotions run through pedagogical practices, and that these can influence how we learn, and that further, the action of teaching can and must be mediated based on this observation. Hence, "it is not only by understanding things logically and rationally that we become able to change them. Changes in behavior will not be produced automatically by our understanding something 'with our

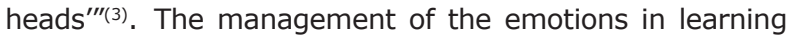
involves the understanding of how the functioning of the brain is processed when it acquires or develops new knowledge in those aspects relating to cognition or a new technical skill, which are differentiated forms of learning(3).

Learning largely depends on each individual's previous experiences with a specified learning object. "These previous knowledges always form the foundation for construction of new knowledge, sometimes they must be integrated to new concepts and information and, sometimes, must be corrected"(5). The learning process is unique to each human being, which facilitates learning for some, and can make it difficult for others. Thus, "we need to investigate the way of understanding the world which the student brings to the classroom, if we are to change it or contribute to its development"(5).

Emotional learning involves complex mechanisms, in which there are divisions between the primary emotions and the secondary emotions ${ }^{(6)}$. The primary emotions originate in the network of neural circuits in the limbic system, the amygdala and the cingulum being their triggers, and it is known that these are essential for individual and collective survival(7). These emotions are fear, anger, sadness, aversion, surprise, happiness and scorn ${ }^{(6)}$.

We know, for example, that the feeling of fear is triggered whenever a potential threat is announced, and we have fight or flight behavior as a response, after assessing the situation and putting ourselves on maximum alert. Anger is linked to being stopped from achieving an objective, and its appearance prepares us to eliminate the source of the frustration. Happiness is triggered when we have a desired situation which occurs as the work of a person, who comes to be seen by us as an ally, which induces a behavior of becoming closer $^{(3,6)}$.

For processing each primary emotion, we use various strategies which consume energy and divert our focus, which can impair or completely impede the learning of something new, when this happens(8). The primary emotions are, as it were, a raw material from which we produce all the others, which are classified in the field of those termed secondary or social emotions, which reflect our behavior. These last 'originate from acquired dispositive representations' but result from the influence of the primary emotions, and vary from one subject to another ${ }^{(3,6-7)}$.

Based on the above, this study's objective was to investigate, in the perception of the nursing lecturers and undergraduate students, aspects of the interaction which take place between the 'feeling' and the 'learning'. The article's contributions shall be to do with learning to know a little more about, and also to value, the role and the importance of the emotions in the process of teaching and learning in nursing, from the perspective of the neurosciences.

\section{Methods}

This research has a qualitative approach and uses the case study, chosen as it has been shown to be useful for creating knowledge on significant characteristics of events experienced in different locales but which have similarities $^{(9)}$.

The investigative settings were two nursing courses, one at the Federal University of Mato Grosso (UFMT) and the other at the Fluminense Federal University (UFF). The subjects researched were lecturers and students from the two courses, who consented to participate in the study. The criteria for inclusion in the research, for the lecturers, was to be a member of the institutions regular teaching staff and to have at least two years' experience as a lecturer; for the students, it was to be properly enrolled in the second semester or later. We excluded students of the first semester due to their low experience in relation to the aspects which interested us in the investigation. The project was approved by the Research Ethics Committee of the Julio Muller University Hospital under decision number 316/2006.

Using triangulation of techniques for data collection, we used a questionnaire, individual interviews, and focus groups. Data collection took place between April and October 2008, and started with the administration of the questionnaire; in the UFF, this was to 25 lecturers and 64 students, and in the UFMT to 19 lecturers and 26 students. At this stage, we aimed to present the objectives, investigate the general data of the population, and raise interest in participating among students and lecturers.

The second technique was the open interview, undertaken with 25 lecturers at the UFF and 19 at the UFMT. Among the students, 15 were interviewed at the 
UFF and 18 at the UFMT. The data was then organized and analyzed with the aim, based on this first analysis, of raising and identifying elements of interest to be explored and extended in the focus groups.

The next stage consisted of the construction of the third and most important data collection instrument - that of the focus groups, a strategy through which we sought to explore the vision and the values of the subjects regarding the research's central issue, that is, the processes of change and innovations which create new subjectivities in the training in the two schools.

In the UFMT we undertook 4 focus groups with lecturers and 3 with students, totalling respectively 19 and 12 participants. At the UFF, 2 focal groups were held with lecturers and 2 with students, a total of 10 lecturers and 12 students. The numerical differences in the FGs at the UFMT and UFF were due to the fact that participation in the research was voluntary. The UFMT had, at the time of the data collection, a total of 45 lecturers on the permanent staff, while the UFF had 70. Regarding the student body, at the same time, there were 234 students at the UFMT and 540 at the UFF.

The focus groups were recorded and transcribed accurately and in full(9). The subjects' accounts were identified as ILE1, with (I) standing for Interview, (LE) lecturer and (1) the number of the subject. The focus groups were identified as FGLE1 through to FGLE4, that is: (FG) for Focus Group, (LE) for Lecturer, and (1) the number of the group. For the students, we used (FG) Focus Group, (STU) Student and (1) number of the group.

Initially, the raw data was analyzed in the light of the framework of Institutional Analysis(10), from which the research's first products resulted. The methodological path traced made it possible to revisit the data, this time analyzing it in the light of the new framework, that of the neurosciences. For the production, we revisited the subjects' discourses (lecturers and students) seeking to identify excerpts in which they referred to feeling in the act of learning, and to identify how the mediation of this process by the teacher or pedagogical strategy which she considers, facilitated or hindered the learning. Based on the identification of these excerpts in the vast material accumulated in the collection process, we moved on to the analysis of its meanings in the light of the framework of the neurosciences.

\section{Results}

In the statements there are two versions - one which points to good previous experiences, and which reminds us that being welcomed in new situations in life can facilitate learning. It makes a really big impact on you to leave the first, second, and third semesters and enter the fourth, because you really feel welcomed by the lecturers [...] because the lecturer relates to us better, when you start with the nursing lecturers, $t$ 's a very good point! [...] the lecturer behaves in a much closer way, more accessible, and he gives opportunities for changes and takes the time to observe the students $[. .$.$] , he sees the situation as a$ whole, he sees us, in terms of nursing (FGSTU5).

The other version points to various aspects. If the experience described above seemed to some to be a respectful and productive pedagogical practice, there are divergent interpretations, stressed as negative for the learning. [...] I'm not enjoying the experience, it might be well-intentioned, the lecturers chose students at random to make groups chosen by them to work using group tutorials. It's just that we end up becoming distant from our group, sometimes they're people who you're not used to working with in the classroom, there's a good side in this, that it prepares you for the professional world. All of a sudden you're working in a different group, which you don't choose, there is this other side to be articulated. It's tiring working in a group. But you have to work in spite of this tiring part, it's part of the training, it's just that sometimes it ends up being very stressful! (FGSTU5)

On reporting situations of group learning in which the strategy of tutorials was used, the participants state that depending on how the objectives of the tutorial are explained to the students, they can re-place it as the center of the process or not. There were students who understood that they were the 'person' at whom the teacher's efforts were directed, but others, who were reminded of the power of the hierarchy, recorded the 'place of the authority of the teacher', which placed them in a 'subordinate' or 'passive' position. The figure of 'authority' recorded in the students' emotional brains, associated with the memory of childhood relationships with people in authority, when negative, brought up negative perceptions and vice-versa.

The results allow one to understand that the interaction established between lecturers and students interferes in the learning. We also understand that the brain learns to cope with difficulties for learning, as long is it is encouraged and prepared for this. [...] I see myself as one of those lecturers who communicates well with the students, I think the interaction is good, I think it is a good horizontal level, so I think it makes an impression, we feel more at ease, not only for clearing up doubts, but the relationship with the teacher improves, I end up trusting more. So, when a lecturer like this calls your attention and pushes you, you push yourself! (FGLE1) 
In those interactions in which fear is present as a primary emotion, it can have an impact on us, make us stop and do nothing, or not want to do anything, for fear of reprisals which may have occurred in similar experiences of ours in the past, and which remain related to types of memory which we have in similar situations which we are experiencing in the situation in question $^{(3,6)}$. [...] that more vertical position (of the lecturer), when he pushes you, you feel oppressed, you feel inferior, you feel scared of clearing up doubts (FGSTU1).

There are lecturers who think of teaching more as a program to be carried out than as a strategy of the subject who teaches, and value repetitive practice, that is, they center the teaching on ways of learning that are more mechanical than sensitive or emotional(11). Being open to the new, to the creative, to the link which appears in the student in the act of learning to care, and which is shown as a strategy created by him to preserve the other which is care, are attitudes which need to be valued by the lecturers who assist and guide students, as when an action opens up other cerebral paths - other than those linked to purely procedural memory - it makes the involvement in the learning more effective for the future nursing professional. But the practice which we thought was really praiseworthy, which woke us up, was when a teacher from the first semester took us into the field, out of the university [...] out of the classroom, out of the laboratory, to interview the professionals, to ask people questions and to be asked questions ourselves, to do things which we knew would give us a lot of work [...] It was a lot of work to leave, catch the bus, and find people who we didn't know in places which we needed to get to know. The fact of everything having been planned, communicated, we knew what we were going to do, they were simple practices but they made big differences, they really were, you know? We felt cared for, part of a learning process which was thought up for us, who were starting, for our needs, this made all the difference. (FGSTU1).

The lecturer who seems to have the greatest skill in 'feeling' the expectations and fears of her students in the learning process is the same person who has already experienced, and who reflects on, her own experience of learning, and who best progresses along the long path that leads to learning. From the moment that we pass through a learning process, whether it's at Master's level or Doctorate level, we had to re-think our practices. So we also went through a process of change, and I think that the changes, [...] to occur in a group or another context, have to happen within ourselves first. From the moment that we begin to change our outlook [...] our action will be different, the approaches will be different, and we can say that there has been a change, which began in ourselves. (ILE4).
When the lecturer praises the progress, she works on the groups' motivation in a proactive way, reinforcing the need for a more attentive view, and as the students can support each other for learning, the practices are remembered by the students as encouraging and positive for the learning. Speaking of the same lecturer [...] there is the issue of her being encouraging [...] that when she sees something good, she tells the student, "I liked what you did, it was very good, your group was marvellous". [...] Giving that encouragement, because it's nice to hear, also because it makes you think that what you're doing matters, the effort that I'm putting in, sometimes you don't get that in the teaching staff, you don't get that support, that recognition, and this is important." (FGSTU2).

\section{Discussion}

The neurosciences have been seeking explanations which can bring the social closer to the biological, and have succeeded in confirming that more intense and meaningful experiences in the learning process do not only transform, but create and re-create cerebral connections at any stage of human life. We appreciate that, in proposing this theoretical line of thinking to explain our data, we are entering a vast and contradictory area in which the biological and social cross paths, as do the comprehensive and more Cartesian sciences; where that which may be measured and checked with instruments meets what is learnt socially and subjectively experienced(3).

In advancing the students' processes and thinking about strategies for reducing fear and increasing selfesteem, the proactive lecturers make use of relational competency, serving the student's learning process. In an internal articulation of the brain, these lecturers use the activation of the prefrontal lobes which, intermediated by the amygdala, helps them to make the 'management of the emotions' necessary for the students' learning(3).

Relational competence has been the object of study in pedagogical practice in nursing, revealing that student nurses consider it to be essential for quality care $^{(12)}$. We also verified that there are studies carried out by nurses, which discuss the teacher's sensitivity and expressiveness, denoting the growing interest in subjective aspects which permeate these professionals' practice $^{(13-14)}$. We also found a study dealing with nurses' emotional competence, with a perspective a little more diverse than that proposed here, that is, we observed that the framework of the neurosciences has been 
little explored in the support for teaching practices in nursing ${ }^{(15)}$.

As a function of the above, we reiterate that knowledge of cerebral functioning and of the different structures which are involved in the learning of different competences can help the lecturer in her task of teaching, making it more concrete for the subject who learns and more pleasurable for the person teaching. This is because we can, as human beings constantly moving forward, develop mechanisms which encourage empathy and identification with our work object, and with the people with whom we interact in the everyday of teaching(3,6).

From the perspective of neuroscience, three types of memory are involved in learning in the different competences, these being: semantic and episodic memory, procedural memory, and emotional memory(3). Cognitive competences become possible thanks to declarative memory, also called 'semantic' or 'episodic'. The neurological substrates of this type of memory are found in the hippocampus and the prefrontal cortex. If there should be ablation of these structures for some reason, any person becomes incapable of acquiring new cognitions, but would be able to carry out routine or repetitive actions perfectly ${ }^{(3,7)}$.

Technical competences related to knowing 'how to do' and skills are based in procedural memory, which is more linked to the operative knowledges and to the mechanical act of repeating actions. This becomes important to the lecturer in nursing, as it makes it clear that procedural memory functions, in the brain, independently of the declarative memory, that is, it calls other areas of the brain apart from those linked to the cognitive competences ${ }^{(3,7)}$. In this way, a student can carry out a technical action perfectly, without ethical care, involving moral or value judgements, such as the protection of the people who are cared for by us, a fact which interferes strongly if we have the evaluative processes of the practical activities of our students as a benchmark.

A lecturer's practice may value, depending on the subjective value registered as procedural or declarative memory, one or another competence, according to the degree to which the lecturer identifies with what she teaches, and also with the responses which she already has as a nurse. To think about human care practices having as one's references the new knowledges from the cognitive sciences can, without doubt, facilitate learning.

This is a competence of teachers who value what they do, their work, and who care about their own learning process, renewing it in the face of new scientific knowledge and in the face of the many needs which the student has if she is to become involved and interested in what is new, in what is unforeseen, and - why not note this - in the tiring process of learning to be a good health professional.

If a student does not learn, it is common for us to think that the problem to be resolved may be cognitive, as the acquisition of new cognitions remains a paradigm in education. It is important to remember, however, that in a healthy brain, all the competences influence each other mutually, as the emotions disturb the acquisition of cognitive, technical or relational competences. Although there are large differences between how the cognitive brain and emotional brain learn, there is plenty of evidence that well-developed and balanced emotional competences influence cognitive and technical learning processes positively, given that cerebral functioning occurs in networks ${ }^{(3,7)}$.

Our 'emotional brain' equips us to receive information, to identify the value it has for us, based also on previous experiences, and also allows us to make social judgments on this information. This social judgment occurs through the interaction between the emotional and cognitive parts of the brain, which leads the individual to "the process of maturation so as to become a responsible citizen"(8). The proactive lecturer, who identifies with the activity of teaching, also learns in this act - and to depend on the apprehension of the 'emotions' which circulate in the group when she is teaching, noting what was positive and what must be repeated for this or that student, and defining what must be discarded or reformulated in her next classes.

In a meta-analysis which included 126 studies published between 1975 and 1988 addressing the relationship between school performance and anxiety, it was confirmed that there is a firm link which emphasizes that highly anxious and stressed people always have worse school performance(16). It has been long known that stress leads to the production of adrenalin by the adrenal glands, a process which influences the brain directly, creating anxiety and fear, which can impede the student in the acquisition of a new cognition or even in the execution of a care technique. The processes of attention are the first to be affected by stress and anxiety and, consequently, affect our learning.

The lecturers who have a more pleasurable experience of teaching human care facilitate the learning, as they understand this activity as a process of subjects becoming relationally closer, which creates empathy at the time of the learning. It is the lecturers 
who undertake this mediation between the learner and the subject or community receiving the care, and they need to be clear on their role in the students' learning.

\section{Final Considerations}

We identified that knowledge of the functioning of the brain and different structures involved in learning of cognitive, technical, emotional and relational competences can help the lecturer in her task of teaching. This new knowledge brings concrete elements which nursing lecturers must master, facilitating the process for the learner and making the teaching process pleasurable. We evidenced that the brain is capable of coping with the difficulties in learning, when stimulated and prepared for this, and that we teachers can influence and develop strategies which encourage and facilitate learning, which depends on the empathy and identification with our work object and with the people with whom we interact in the everyday of teaching.

The lecturer needs to enjoy the interaction between the subjects, and she is also expected to take pleasure in what she does - teaching to care - and identifying with humane care. In the case of care practices for the other, there are varying demands when we act as nurses only, and when we are lecturers teaching to care. There are more people and needs placed in a relationship which happens when three subjects meet - the student, the lecturer and the person who is cared for. The lecturer needs to care for the student and for the subject who is being cared for, who is doubly fragilized, due to being in the hands of a 'learner' at a time of vulnerability. The emotionally-competent lecturer uses mechanisms which value the subject learning to be a nurse, and value nursing as well, remembering that this is a human activity which demands what seems to be the most revolutionary element in the process of caring for another: the notion of preserving the species through altruism.

\section{References}

1. Organisation de Coopération et de Développemente Économiques (OCDE). Comprendre le cerveau: vers une nouvelle science de l'apprentissage. [Internet] 2002. [acesso 14 fev 2012]. Disponível em: http://prea2k30. risc.cnrs.fr/ressources/accesfichier/16.

2. Organisation de Coopération et de Développemente Économiques (OCDE). Comprende le cerveau: naissance d'une science de l'apprentissage. [Internet] 2007. [acesso 14 fev 2012]. Disponível em: http://www.oecd. org/dataoecd/10/25/40583325.pdf
3. Chabot D, Chabot M. Pedagogia Emocional: sentir para aprender. São Paulo (SP): Sá Editora; 2005. 287 p. 4. Perrenoud P. Construindo competências. Nova Escola; 2000 Set:19-31.

5. Bettancourt L, Munoz LA, Merighi MAB, Santos MF. Nursing teachers in clinical training areas: a phenomenological focus. Rev. Latino-Am. Enfermagem. 2011;19(5):1197-204.

6. Ekman P. Emotion in the human face. $2^{\mathrm{a}}$ ed. Cambridge: Cambridge University Press; 1982.

7. Damásio A. O erro de Descartes: emoção, razão e cérebro humano. São Paulo (SP): Companhia das Letras; $1996.330 \mathrm{p}$.

8. Servan-Schreiber D. Goals for education? Emotional Competency. In: Preliminary synthes first high level forum Learning Sciences and Brain Research: potential implications for education policies and practices brain mechanisms and early learning. New York City: Sackler Institute; 2000. p. 16-17.

9. Minayo MCS. O Desafio do Conhecimento: pesquisa qualitativa em saúde. 9a ed. São Paulo (SP): Hucitec; 2010. 406 p.

10. Baremblitt G. Compêndio de análise institucional e outras correntes. Rio de Janeiro (RJ): Rosa dos Tempos; 1996.

11. Morin E, Ciurana ER, Motta RD. Educar na era planetária: o pensamento complexo como método de aprendizagem no erro e na incerteza humana. São Paulo (SP): Cortez: Brasília, DF: UNESCO, 2003.

12. Lopes RCC, Azeredo ZAS, Rodrigues RMC. Relational skills: needs experienced by nursing students. Rev. LatinoAm. Enfermagem. Nov.-Dez. 2012;20(6):1081-90.

13. Terra MG, Gonçalves MG, Santos EKA, Erdmann AL. Sensibility in the Relations and Interactions of Teaching and Learning to Be and Do Nursing. Rev. Latino-Am. Enfermagem. Mar.-Abr. 2010;18(2):203-9.

14. Romano CC, Alves LA, Secco IAO, Ricz LNA, Robazzi MLCC. The expressiveness of a university professor in his classroom performance: analysis of verbal resources and implications for nursing. Rev. Latino- Am. Enfermagem. Set.-Out. 2011;19(5):1188-96.

15. Agostinho LMCF. Competência Emocional em enfermeiros: um estudo em hospitais públicos [dissertação de mestrado]. Aveiro (Portugal): Secção Autónoma de Ciência Sociais, Jurídicas e Políticas/ Universidade de Aveiro; 2008. 324 p.

16. Seipp B. Anxiety and academic performance: a meta analisys of findings. Anxiety Res. June 1991;4(1):27-41.

Received: Aug. 10 2012 Accepted: Apr. $11^{\text {th }} 2013$ 